\title{
Laboreal
}

Volume $4 \mathrm{~N}^{\circ} 2$ | 2008

A inovação

\section{Modus Laborandi o los libros sobre el trabajo}

Modus Laborandi ou os livros sobre o trabalho

Modus Laborandi ou les ouvrages sur le travail

Modus Laborandi or the books about work

Jesús Villena

\section{OpenEdition}

\section{Journals}

Electronic version

URL: http://journals.openedition.org/laboreal/11480

DOI: $10.4000 /$ laboreal. 11480

ISSN: 1646-5237

\section{Publisher}

Universidade do Porto

\section{Electronic reference}

Jesús Villena, «Modus Laborandi o los libros sobre el trabajo », Laboreal [Online], Volume 4 N² 2 | 2008 Online since 27 September 2019, connection on 24 September 2020. URL : http://

journals.openedition.org/laboreal/11480; DOI : https://doi.org/10.4000/laboreal.11480

This text was automatically generated on 24 September 2020.

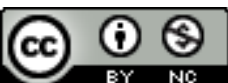

Laboreal está licenciado com uma Licença Creative Commons - Atribuição-NãoComercial 4.0 Internacional. 


\title{
Modus Laborandi o los libros sobre el trabajo
}

\author{
Modus Laborandi ou os livros sobre o trabalho \\ Modus Laborandi ou les ouvrages sur le travail \\ Modus Laborandi or the books about work
}

Jesús Villena

El mundo del trabajo es el laboratorio en el que se experimenta la sociedad

Christophe Dejours

1 El próximo mes de enero-y después de dos años de preparación-, los libros de Modus Laborandi saldrán al encuentro de sus lectores. Estos libros han sido cuidadosamente elegidos para formar parte de un proyecto que persigue mejorar la calidad de la reflexión, la práctica profesional y la investigación en el ámbito de las ciencias humanas y sociales del trabajo en español.

2 ¿Por qué una editorial que quiere publicar este tipo de libros? Salvo honrosas iniciativas electrónicas como Laboreal, Activités o Pistes, en Modus tenemos la impresión de que resulta muy difícil encontrar publicaciones que hablen del mundo de trabajo con un cierto rigor, o dicho de un modo más exacto, que hablen de ciertos aspectos del trabajo prácticamente ausentes de la literatura científica en español. Nos parece desoladora la calidad del pensamiento que se ofrece en las librerías sobre organización del trabajo, ergonomía o psicodinámica del trabajo, por poner unos pocos ejemplos muy llamativos. También nos sorprende que la mayoría de los textos que hablan de las crecientes exigencias físicas o psicológicas, o de las consecuencias que estas tienen para salud de las personas se presenten en forma de libros de autoayuda o que hayan encontrado terreno abonado en ese extraño tipo de publicaciones al que denomino literatura aeroportuaria para managers necesitados de explicaciones de rápida digestión. Hubo sin embargo un tiempo en el que se produjo en España una cierta abundancia de literatura sobre el trabajo, quizá debido al empuje de ciertos organismos oficiales y de sus departamentos de publicaciones. Sería injusto decir ahora que en España no se publican o se han publicado libros relevantes en ciencias sociales 
del trabajo ¿es necesario recordar que, además de los grandes clásicos como Friedman, la obra de Castells, Touraine, Reynaud, Pahl, Meda, Sabel, Offe, Gorz, Coriat (y otros tantos) todavía se puede encontrar en bibliotecas? Pero ya no está en las librerías. Y aunque sea cada vez más difícil encontrarlos, no sería justo ignorar la encomiable labor de reedición y apuesta por ciertos valores del pensamiento que realizaron -y realizan con algunas reediciones-, las editoriales españolas que tienen sus raíces en la tradición editorial argentina o mejicana. Pero insistimos en que sólo tangencialmente se trata de publicaciones que exclusivamente hablan del trabajo, ahora más que nunca.

3 En estos tiempos, - y de forma un tanto oportunista -, algunas editoriales de nuestro país publican trabajos que quieren dar respuesta a debates sociales muy puntuales en el territorio del ensayo (La corrosión del carácter, de Richard Sennet, en Anagrama, por no hablar de Jeremy Rifkin), surgen scoops mediáticos (El acoso moral, de Marie-France Hirigoyen, en Paidós), o se aplasta al profesional con abundantísimos prontuarios normativos aparecidos al abrigo de la legislación sobre prevención de riesgos laborales, otro subgénero que reitera ad nauseam el abanico de normas y recomendaciones preventivas disponibles en los organismos oficiales. Estos manuales, conjugados con una severa pobreza formativa, llevan a la aplicación de recetas carentes de toda explicación teórica o metodológica. Como es natural, estas prácticas impiden comprender las causas del problema que se estudia y hacen perder credibilidad profesional a todo el colectivo de profesionales y científicos dedicados al estudio y transformación del trabajo. No podemos desentrañar las causas de esta situación en una pocas líneas. Resulta en cualquier caso paradójico que todos los estudios y encuestas oficiales hablen del trabajo como la primera preocupación de los ciudadanos, preocupación bien justa en estos tiempos en los que el empleo está en el centro de todos los debates : pero insistimos, hablar o pensar el trabajo no es únicamente una reflexión sobre el empleo, más bien el problema del desempleo sería probablemente una de las consecuencias de la ausencia de reflexión pública sobre las cuestiones del trabajo, de su organización, de los saberes y conocimientos que se movilizan en la empresa, de la productividad, de la calidad de vida en trabajo, de la interacción humana con la tecnología, etc... Paradójicamente, junto a esta desaparición de la reflexión escrita, los directores de cine, los fotógrafos, los documentalistas, los bloggers están dando rienda suelta a nuevas formas de análisis y expresión crítica de lo que ocurre dentro de las paredes de fábricas y oficinas. Al mismo tiempo, con mayor o menor fortuna, no pocos periodistas y gurús del mundo de las escuelas de negocios comienzan a llenar los suplementos dominicales de análisis que resulta difícil encontrar en otros lugares.

4 En el ámbito de la literatura de carácter profesional la situación es alarmante. Si hablamos de ergonomía, por poner un ejemplo, no resulta infrecuente que en las bibliografías universitarias españolas se siga citando como únicos textos de referencia ciertos trabajos de la ergonomía francesa de los años 60 - excelentes, aunque ya un poco envejecidos -, de "novedades" que reinventan con más pena que gloria el método LEST, los Fundamentos de Ergonomía de Zinchenko y Munipov (Editorial Progreso de Moscú) o La ergonomía en acción de Oborne, publicado por la Editorial Trillas de Méjico hace ya unos treinta años. A pesar de que las exigencias preventivas en las empresas españolas son ahora mayores que nunca, no existe ni un solo texto de alto nivel al que referirse en cuestiones teóricas o metodológicas sobre ergonomía. Así mismo, la ausencia de referencias científicas sobre técnicas de investigación sobre el terreno ha empobrecido las investigaciones de forma escandalosa hasta conducir la calidad de los 
datos y su análisis a la trivialidad. Si nos extendemos al ámbito del riesgo, resulta difícil salir de la órbita de Ulrick Beck (La sociedad del riesgo. Hacia una nueva modernidad, editorial Paidós) para encontrar otras formas de reflexión de detalle sobre la acción humana ante las situaciones complejas de riesgo, especialmente en el ámbito industrial, en los transportes, en los hospitales. Sorprendentemente, todos los meses se produce alguna catástrofe en la que el fallo humano parece ser el diagnóstico unánime.

El proyecto editorial de Modus Laborandi quiere llenar este vacío en el ámbito de las bibliografías científico-técnicas sobre el trabajo y responder a una demanda de carácter social. El plan editorial contempla la publicación de la obra de Reason y Perrow, la de Dejours y Clot, la de Maggi y a Askenazy. Para los interesados en la actividad humana en situaciones complejas de alto riesgo, encontrarán muchas respuestas en la obra Dekker, Hollnagel, Amalberti y Dörner. Petroski, Guillén y Dujarier también aparecerán en el catálogo de la editorial. Para los ergónomos, dos obras imprescindibles: Comprender el trabajo para transformarlo. La práctica de la ergonomía de Guérin, Laville, Daniellou, Duraffourg y Kerguelen y el Manual de Ergonomía, dirigido por Pierre Falzon.

6 Modus Laborandi convoca a psicólogos, ergónomos, sociólogos, economistas, ingenieros, médicos, organizadores de la producción, especialistas en seguridad o arquitectos. Se le pide que piensen y escriban para el gran laboratorio del trabajo, en el que se experimenta la sociedad. Esperamos de los lectores de Laboreal sus contribuciones, sus críticas y su ayuda.

\section{AUTHOR}

\section{JESÚS VILLENA}

Ergotec Modus Laborandi Emilio Carrere 4, 3ํㅡ 28015 Madrid, Spain

www.moduslaborandi.com

buzon@moduslaborandi.com 